\title{
POLÍTICAS FEDERAIS DE TRANSPORTE PÚBLICO: A DIFUSÃO E IMPLANTAÇÃO DO SISTEMA BRT (BUS RAPID TRANSIT) EM CIDADES BRASILEIRAS
}

\author{
Raphael Félix Ribeiro Faria \\ Universidade Federal Fluminense, Instituto de Ciências da Sociedade e Desenvolvimento Regional \\ Campos dos Goytacazes, RJ, Brasil \\ raphaelfelixr@hotmail.com
}

\begin{abstract}
RESUMO
Este trabalho tem o objetivo de apontar as políticas públicas federais que culminaram na difusão e implantação do Sistema Bus Rapid Transit (BRT) em cidades brasileiras e discutir a atuação desse tipo de transporte no âmbito da organização do espaço urbano. Com esse intuito, é contextualizada a problemática do transporte urbano e as políticas de mobilidade urbana que implicam em interesses e conflitos no transporte e nos usos. A partir de pesquisas bibliográficas, levantamento de dados, entrevistas a usuários de transporte e órgãos públicos, e observações em campo, analisa-se como o sistema BRT tem sido difundido em cidades de diferentes realidades espaciais, sociais e econômicas. Os resultados do trabalho mostram que o BRT é um instrumento que ameniza a problemática da mobilidade urbana, mas amplia os conflitos de interesses entre os agentes sociais.
\end{abstract}

Palavras-chave: Mobilidade urbana. Políticas públicas. Conflitos sócio-espaciais.

\section{FEDERAL PUBLIC TRANSPORT POLICIES: THE DIFFUSION AND IMPLEMENTATION OF THE BRT SYSTEM (BUS RAPID TRANSIT) IN BRAZILIAN CITIES}

\begin{abstract}
This work has the objective of pointing out the federal public policies that culminated in the diffusion and implantation of the Bus Rapid Transit System (BRT) in Brazilian cities and to discuss the performance of this type of transport in the scope of urban space organization. With this aim, the urban transport problem and the urban mobility policies are contextualized, implying interests and conflicts in transportation and use. Based on bibliographical research, data collection, interviews with transport users and public agencies, and field observations, it is analyzed how the BRT system has been diffused in cities of different spatial, social and economic realities. The results of the study show that BRT is an instrument that softens the problematic of urban mobility, but it widens the conflicts of interest between the social agents.
\end{abstract}

Keywords: Urban mobility. Public policy. Socio-spatial conflicts.

\section{INTRODUÇÃO}

Os sistemas de transportes públicos como o BRT - Bus Rapid Transit - Trânsito Rápido por Ônibus, se tornaram instrumentos que constituem o processo paulatino das políticas federais de mobilidade urbana. A partir desse processo, são difundidos esses modelos nas cidades brasileiras de diversos contextos socioespaciais e que, em alguns casos, já reforçam a histórica ineficiência da gestão do transporte público urbano e, em outros, revelam contribuições à população.

Para entender os atuais avanços das políticas de mobilidade urbana, é necessário elucidar a problemática do transporte público no Brasil elencando um conjunto de fatores como a intensificação da urbanização (e consolidação da rede urbana) a partir de 1970, a intensificação do processo de industrialização, incentivos à indústria automobilística e, principalmente, o desinteresse político em investir em transporte coletivo.

$\begin{array}{llllll}\text { Caminhos de Geografia } & \text { Uberlândia - MG } & \text { v. 19, n. } 67 & \text { Set/2018 } & \text { p. 361-373 } & \text { Página } 361\end{array}$


A partir da análise das contribuições teóricas de Villaça (1999) e Vasconcellos (2013) sobre políticas públicas e transporte urbano, respectivamente, é possível entender que o processo de incorporação de políticas voltadas para o transporte público nos planejamentos municipais ocorreu após a exigência constitucional do Plano Diretor, em 1988, com a exceção de alguns centros urbanos como Curitiba-PR e São Paulo-SP que já contavam com planos de transportes. Antes, eram adotados os chamados planos viários que se restringiam em viabilizar e atender à demanda de veículos particulares, contemplando parcialmente o transporte público coletivo.

Essa acentuada defasagem da gestão pública aliada à intensificação da urbanização deixaram latente o gargalo do transporte público: o espraiamento da área urbana aumentou o tempo e a distância dos deslocamentos da população, enquanto que as políticas públicas não acompanharam essa evolução. Sem transporte público efetivo, algumas camadas da população recorreram ao uso do transporte particular.

Segundo Rochefort (2008) a urbanização desenfreada promoveu a evolução dos bairros ricos, mediante o distanciamento em relação às áreas centrais do sítio urbano, e as ocupações precárias nas áreas periféricas. Esse fenômeno ganhou fôlego através dos programas sociais de regularização e de construção de moradias para população de renda baixa e da expansão dos loteamentos fechados e condomínios residenciais.

Para o autor, a "exclusão periférica das zonas residenciais" dos trabalhadores de diversas escalas da hierarquia empresarial, acentuou a necessidade do deslocamento na cidade. Rochefort (2008, p.112) enfatiza que a falta de recursos do poder público [assim como a ausência de políticas públicas e o desinteresse dos governantes] não permitiu desenvolver o setor de transportes por causa do constante aumento da demanda de usuários, e por isso

\begin{abstract}
as populações abastadas optaram, então, pelo carro individual, cujo número aumenta rapidamente desde 1980; a massa dos habitantes com renda modesta aperta-se nos ônibus longamente esperados nos pontos ou se utiliza de sistemas informais de transporte que se multiplicam diante da penúria dos serviços legais (ROCHEFORT, 2008,p. 112).
\end{abstract}

Com a precarização do transporte público e o aumento do tempo e da distância dos deslocamentos na cidade, condicionou-se o levante da utilização de veículos particulares a partir de 1960. No gráfico 1 é possível constatar a evolução dos licenciamentos de veículos automotores no período entre 1960 até 2015. Compõe essa listagem os licenciamentos dos automóveis, veículos comerciais leves (picapes, furgões e vans), caminhões e ônibus.

Gráfico 1: Autoveículos licenciados entre 1960 e 2015.



Fonte: Anfavea (2016). Organizado pelo autor.

$\begin{array}{llllll}\text { Caminhos de Geografia } & \text { Uberlândia - MG } & \text { v. 19, n. } 67 & \text { Set/2018 } & \text { p. 361-373 } & \text { Página } 362\end{array}$


Entre 1960 e dezembro de 1969, foram licenciados 1,4 milhão de automóveis ante 39,3 mil ônibus. Na década de 1970 o número de automóveis aumentou quase cinco vezes, 6,1 milhão, enquanto que os ônibus licenciados chegaram a 81,5 mil. O levante da dívida externa e do déficit público no Brasil em 1980 retraíram os investimentos na indústria, justificando a leve diminuição dos licenciamentos de carros em relação ao período anterior, cerca de 400 mil (ANFAVEA, 2016).

Em 1990, mesmo com a inflação em alta e as oscilações do valor do Real em relação ao Dólar, a indústria automobilística comemorou a expansão do mercado: foram 10,5 milhões de automóveis licenciados ante 138,8 mil ônibus. Segundo o IBGE, a população urbana chegou a 110,8 milhão em 1991. Não há dados estatísticos sobre o déficit do transporte público na época, mas é possível diagnosticar que, considerando o número da população urbana no país dividido pela frota de ônibus licenciada no período (1990 - 1999), havia um ônibus para cada grupo de 798,2 passageiros.

Entre 2000 e dezembro de 2009, o cenário político e econômico influenciou no crescimento dos setores do segmento produtivo e de serviços. O aumento da renda e do crédito direto ao consumidor, facilidades nas transações financeiras, os incentivos fiscais, como desoneração à indústria automobilística, culminaram no expressivo aumento de $64 \%$ dos licenciamentos de automóveis em relação ao período anterior. Entre 2010 e 2015, a quantidade de automóveis licenciados já supera a registrada na década anterior (ANFAVEA, 2016). Houve, portanto, forte apoio do Governo Federal com a indústria automobilística, posição divergente à Política Nacional de Mobilidade Urbana (Lei $\mathrm{n}^{0} 12.587 / 2012$ ) que prioriza os serviços de transporte público coletivo e os modos de transporte não motorizados, sendo que os desdobramentos para os investimentos em infraestrutura de transporte público só foram efetivados após sua criação através de programas subsidiados por recursos do Programa de Aceleração do Crescimento 2 (PAC 2) que, hoje, seguem as diretrizes da lei.

A problemática do transporte urbano no Brasil, portanto, também é resultado das pretéritas políticas públicas que fomentaram o rodoviarismo e que tornaram a indústria automobilística protagonista do cenário político e econômico no país. Além disso, as dificuldades da mobilidade e acessibilidade ao espaço urbano são evidenciadas no cotidiano da população, e se devem, dentre outros fatores, às discrepâncias sociais e a expansão desordenada das áreas urbanas.

Outra questão a ser levantada, e que caracteriza o momento histórico dessa problemática, consiste nas manifestações de protestos em meio às ineficientes políticas de transportes e nos recorrentes aumentos das tarifas, como a "revolta da catraca" em 2004, 2005 e 2010 em Florianópolis - SC, os protestos em junho de 2013 que se disseminaram no país e a greve dos trabalhadores do transporte público, como a de São Paulo - SP em 2014. A maioria desses movimentos reacendeu a insatisfação da população com as condições do transporte nas cidades e movimentou as discussões sobre políticas municipais e federais de mobilidade urbana.

Mesmo com a implementação da Lei Federal no12.587/2012, da Política Nacional de Mobilidade Urbana (PNMU), os protestos reuniram milhares de pessoas nas ruas das cidades brasileiras nos dois anos seguintes a sua aprovação. Foi a partir das diretrizes dessa lei que os investimentos em infraestrutura de transporte urbano, financiados pelo PAC 2, tornaram-se exequíveis, a destacar os investimentos para implantação do sistema BRT em cidades de porte médio - com população entre 100 mil a 500 mil habitantes (IBGE 2014), e em grandes cidades, com população maior que 500 mil habitantes. No entanto, algumas cidades implantaram o BRT antes da aprovação da PNMU, a serem destacadas no decorrer deste trabalho.

Segundo o discurso do poder público, o sistema BRT surge como uma alternativa para melhorar o transporte urbano, e a difusão desse modelo no Brasil foi possível através de políticas de financiamento do transporte público, promovidas pelo governo federal a partir de 2007 e efetivadas com a PNMU em 2012 (MINISTÉRIO DO PLANEJAMENTO, 2015). Desde então, inúmeras cidades, de diferentes contextos socioespaciais, elaboraram projetos para implantação do sistema BRT, como em cidades de porte médio - que, portanto, possuem áreas e populações menores a serem contempladas - e em cidades de maior porte - onde já se apresentam defasagem operacional. Dessa forma, indaga-se sobre as circunstâncias ideais para a implantação do sistema BRT nas cidades.

A partir de estudos desenvolvidos, uma das hipóteses levantadas é a possível inadequação do projeto BRT em algumas cidades, devido à falta de infraestrutura viária que dê suporte à eficiência do sistema, e até mesmo a ausência de planos de transporte público urbano que 
tornasse efetivo o planejamento a longo prazo. Ou seja, a disseminação do sistema BRT em cidades brasileiras poderia ser tratado como um modelo de transporte proveniente da propaganda ou city marketing de Curitiba, de contextos socioespaciais distintos das demais cidades que já implantaram ou que ainda vão implantar. Uma questão que problematiza a discussão seria a estratégia e o marketing que dão significado a difusão favorável do BRT conduzida, principalmente, por políticos, indústria de carrocerias de ônibus, empresas concessionárias de transporte público urbano e agentes fundiários urbanos - na produção, valorização e apropriação do espaço.

Nesta pesquisa, será traçado um diagnóstico da difusão do BRT no Brasil, com apontamentos sobre a implantação do sistema em algumas cidades onde se eclodiu problemas de diversas ordens envolvendo diferentes agentes sociais, que fomentaram o interesse em observá-los e analisá-los para, assim, tentar compreender como este sistema é difundido no contexto das políticas públicas e da organização do espaço.

\section{ESTATUTO DA CIDADE, MINISTÉRIO DAS CIDADES E A LEI DA POLÍTICA NACIONAL DE MOBILIDADE URBANA: EVOLUÇÃO DAS POLÍTICAS DE MOBILIDADE URBANA}

A Constituição de 1988 delegou aos municípios a responsabilidade em desenvolver políticas de transporte urbano, sinalizando o afastamento da União em investimentos no setor (VILLAÇA, 1999; VASCONCELLOS, 2013). O tema só voltou às políticas federais a partir da criação do Ministério das Cidades (2003) e dos investimentos através do Programa de Aceleração do Crescimento (2007), principalmente para atender grandes eventos como, por exemplo, os Jogos Pan-americanos, a Copa do Mundo no Brasil e os Jogos Olímpicos do Rio de Janeiro. Mas, foi com a Política Nacional de Mobilidade Urbana que se efetivou, teoricamente, a obrigação dos municípios em elaborar planos de transporte público, como será analisado.

Com objetivo de reordenar as políticas públicas para o desenvolvimento urbano, o inciso primeiro do artigo 182 da Constituição Federal (1988), tornou obrigatória a elaboração do Plano Diretor nas cidades com mais de 20 mil habitantes. Os princípios estabelecidos preveem que o Plano Diretor reja(?) o uso e o parcelamento do solo urbano, assim como os demais ordenamentos territoriais inerentes ao espaço urbano, como especificado no Estatuto da Cidade (Lei no10.257/2001).

Para Maricato (2011) as diretrizes do Estatuto da Cidade reforçaram o Plano Diretor como instrumento básico para a política de desenvolvimento social e expansão urbana. O processo de urbanização, os problemas urbanos e as pressões sociais (que colaboraram para a criação dos artigos 182 e 183 da Constituição) foram os pressupostos que embasaram as discussões sobre o Estatuto da Cidade durante 12 anos, tendo sido implementado em 2001 através da Lei ํo10.257 (SENADO FEDERAL, 2016).

Os artigos $2^{\circ}$ e 39 do Estatuto da Cidade ajudam a esclarecer que o Plano Diretor é instrumento fundamental para a garantia dos direitos do cidadão como o acesso à cidade e a equipamentos públicos essenciais à qualidade de vida. Segundo o artigo 40 do Estatuto da Cidade (Lei no 10.257/2001) "o plano diretor, aprovado por lei municipal, é o instrumento básico da política de desenvolvimento e expansão urbana".

Para Maricato (2011) as contradições entre planos diretores implementados e as leis são evidenciadas nas políticas que colocam a "terra urbanizada" como apropriação do capital imobiliário. Para a autora a questão da moradia e a "terra urbanizada" provida por infraestrutura e serviços básicos, são essenciais para efetivar as diretrizes que embasam o Plano Diretor, embora os interesses públicos sejam frequentemente submetidos aos privados. Se a função social da propriedade urbana não atinge os objetivos expostos nas leis apresentadas, segundo Maricato (2011, p.118), o Plano Diretor deixa de ser um instrumento de orientação da gestão para cumprir o papel ideológico intrínseco à classe dominante.

Embora as diretrizes constitucionais previssem o desenvolvimento de planos de desenvolvimento urbano e de transportes (art. 2 - Lei 10.257/2001) através do Plano Diretor, durante a década de 1990, a falta de políticas e de recursos nos municípios ampliaram os gargalos do transporte público urbano (VASCONCELLOS, 2013).

A preocupação com a política de transporte urbano voltou à esfera federal através da criação do Ministério das Cidades em 2003, que abrigou a Secretaria de Mobilidade e o Departamento

$\begin{array}{llllll}\text { Caminhos de Geografia } & \text { Uberlândia - MG } & \text { v. 19, n. } 67 & \text { Set/2018 } & \text { p. 361-373 } & \text { Página } 364\end{array}$


Nacional de Trânsito (Denatran). O ministério preencheu um vazio institucional que retirava a esfera federal da discussão sobre políticas públicas urbanas (VASCONCELLOS, 2013; MARICATO, 2006, p. 214).

Segundo Vasconcellos (2013) e Maricato (2006, 2009, 2011) os movimentos sociais se levantaram ante as questões essenciais da reforma urbana como habitação, saneamento, transportes, que levaram a importantes discussões em torno do desenvolvimento das cidades a exemplo das conferências nacionais, estaduais e municipais sobre as cidades, fomentadas pelo Ministério das Cidades.

A partir de 2004 foram inseridas à pasta do novo Ministério, comitês técnicos sobre trânsito, mobilidade urbana e transporte urbano. Mas, como destacado por Vasconcellos (2013, p.92-93) as temáticas incorporadas perderam espaço para as áreas de habitação e saneamento, que têm mais recursos e maior atenção dos políticos e empresários. O autor considera que "as novas forças políticas" não demonstraram interesse no tema de transporte urbano. Por isso, a Secretaria de Mobilidade (SEMOB - Ministério das Cidades), criada em 2003, teve sua atuação limitada, minimizando as discussões sobre a elaboração de uma política nacional que regulamentasse o transporte público urbano. No entanto, mesmo com a limitação política, Duarte (2007) credita à SEMOB o papel fundamental para elaboração do "Estatuto da Mobilidade Urbana", que deu base à Política Nacional de Mobilidade Urbana (PNMU).

Após 9 anos em formulação , em 2012 foi aprovada a Política Nacional de Mobilidade Urbana (PNMU), Lei $\mathrm{n}^{\circ} 12.587 / 2012$. Os principais objetivos da lei é contribuir para o acesso universal à cidade, condicionar a execução da acessibilidade, promover a equidade no uso do espaço público de circulação e integrar à política de desenvolvimento urbano e respectivas políticas setoriais de habitação, saneamento básico, planejamento e gestão do uso do solo.

A PNMU está fundamentada nos princípios da eficiência à acessibilidade universal, no desenvolvimento socioeconômico, assim como a equidade no uso do espaço público de circulação (art. 5은 LEI №12.587/2012). As diretrizes desta lei são orientadas pela integração com a política de desenvolvimento urbano e as políticas de habitação, saneamento, planejamento e gestão do uso do solo com 0 intuito de reduzir as desigualdades sociais (art. $6^{0}$ e $7^{\circ}$ LEI №12.587/2012). Essas diretrizes fazem parte das propostas encabeçadas por movimento sociais, acadêmicos e profissionais da área, e das Conferências sobre as cidades que promoveram a discussão sobre elaboração de um plano de transporte, a partir de 2003 (VASCONCELLOS, 2013). Para Duarte (2007), as leis de uso e ocupação do solo precisam integrar as leis de mobilidade urbana, assim como a PNMU, que orienta a otimização, o uso e o deslocamento no território.

A PNMU atribui aos municípios o planejamento e a execução das políticas de mobilidade urbana, assim como a regulamentação dos serviços de transporte urbano (art. 18). O artigo 21 diz que o planejamento, a gestão e a avaliação dos sistemas de mobilidade devem contemplar os objetivos de curto, médio e longo prazo, estipulados nos Planos de Mobilidade Municipal. Já o artigo 24 delega aos municípios a obrigação de elaborar o Plano de Mobilidade e incorporar ao Plano Diretor. No artigo 24, especifica que:

o Plano de Mobilidade Urbana é o instrumento de efetivação da Política Nacional de Mobilidade Urbana e deverá contemplar os princípios, os objetivos e as diretrizes desta Lei, bem como: (...)

$\S 1^{\circ}$ Em Municípios acima de 20.000 (vinte mil) habitantes e em todos os demais obrigados, na forma da lei, à elaboração do plano diretor, deverá ser elaborado o Plano de Mobilidade Urbana, integrado e compatível com os respectivos planos diretores ou neles inserido. (...)

$\S$ 3으 $\mathrm{O}$ Plano de Mobilidade Urbana deverá ser integrado ao plano diretor municipal, existente ou em elaboração, no prazo máximo de 3 (três) anos da vigência desta Lei.

$\S 4^{\circ}$ Os Municípios que não tenham elaborado o Plano de Mobilidade Urbana na data de promulgação desta Lei terão o prazo máximo de 3 (três) anos de sua vigência para elaborá-lo. Findo o prazo, ficam impedidos de receber recursos orçamentários federais destinados à mobilidade urbana até que atendam à exigência desta Lei (POLÍTICA NACIONAL DE MOBILIDADE URBANA, LEI $12.587 / 2012)$. 
Portanto, o artigo 24 institui o Plano de Mobilidade Urbana como instrumento de desenvolvimento urbano e social. É através da elaboração do Plano que as prefeituras poderão adquirir recursos da União para efetivação das suas políticas de mobilidade urbana. O capítulo seguinte deste trabalho analisa a difusão do BRT em cidades brasileiras como em decorrência da Lei Federal

\section{A DIFUSÃO E IMPLANTAÇÃO DO SISTEMA BRT EM CIDADES BRASILEIRAS E SUAS IMPLICAÇÕES NO TRANSPORTE PÚBLICO URBANO}

O modelo do BRT tem sido difundido no exterior ao longo dos 42 anos de sua existência e, no Brasil o processo é intensificado em meados dos anos 2000 e, através do Programa de Aceleração do Crescimento (PAC), implantado em cidades com distintas características socioespaciais. Este processo tem origem na política urbana desenvolvida em Curitiba - PR, que exportou seus arquétipos de renovação da mobilidade e de planejamento urbanos embasados em parâmetros específicos para o uso e ocupação do solo urbano. A partir dessas questões, este capítulo discute a origem e difusão do Sistema BRT em cidades brasileiras, apresentando elementos que permitam contextualizar os resultados em cidades de diferentes portes e realidades.

Em Curitiba, desde a década de 1940, um conjunto de fatores como o expressivo aumento da população urbana, o crescimento do número de veículos em circulação, as recorrentes instalações de estabelecimentos comerciais e fabris em áreas consideradas impróprias, a proliferação de loteamentos clandestinos e o surgimento das primeiras favelas, exigiram maior coordenação dos mecanismos institucionais ligados à produção do espaço urbano (IPPUC, 2015). Então, foi elaborado em 1943 o Plano Agache e, duas décadas depois foi efetivado o Plano Diretor.

As principais transformações ocorridas no espaço urbano de Curitiba remetem a efetivação do Plano Diretor em 1966, que orientou o processo de crescimento espacial da cidade de forma linear. Ou seja, a adoção de um modelo linear de expansão urbana promoveu a construção de um sistema viário contínuo interligando áreas isoladas da malha urbana, transformando-as em novas ligações viárias (IPPUC, 2015). Por isso, uma das funções básicas que fundamentou o Plano Diretor foi a hierarquização do sistema viário. O uso do solo urbano e o transporte coletivo completam o tripé que orienta o Plano. Segundo o Instituto de Pesquisa e Planejamento Urbano de Curitiba (IPPUC, 2015) o zoneamento de uso do solo, a regulamentação dos loteamentos e a renovação urbana são exemplos das diretrizes que foram adotadas.

Dentre algumas das medidas executadas, a mais emblemática do planejamento urbano em Curitiba foi a construção do Sistema Estrutural (figura 2), que é um conjunto trinário de vias paralelas, sendo que a via central é composta por canaleta exclusiva para circulação de ônibus expressos; nas laterais dessa via central localizam vias de trânsito lento destinadas para o acesso ao comércio e as moradias paralelas ao Eixo Estrutural; as outras duas vias que compõem o conjunto trinário são paralelas à via central e caracterizadas pelo trânsito de maior intensidade no sentido bairro/centro e centro/bairro (IPPUC, 2008).

Segundo o ex-prefeito de Curitiba - e um dos principais envolvidos na elaboração do Plano Diretor, o arquiteto Jaime Lerner, o objetivo da implantação do sistema trinário de vias foi o de estabelecer parâmetros para o uso do solo urbano, como a localização das atividades de comércio e de serviços, compatíveis com a crescente demanda populacional (LERNER, 2013, p. 20). O Sistema Estrutural, portanto, funcionou como eixo de organização da produção espacial de maneira a fomentar a evolução constante da cidade, alinhando-se aos objetivos do planejamento urbano (IPPUC, 2015). Pode-se dizer, com base em Harvey (1996), que houve uma mobilização de agentes sociais específicos que minimizou os conflitos sociais para agilizar a organização do espaço urbano sob a coordenação do Executivo Municipal.

O zoneamento proposto asseguraria a integração espacial da cidade, pois além de ser um "agente catalisador e promotor do desenvolvimento com efeitos multiplicadores", agilizou a indução de alguns setores para o adensamento populacional enquanto que outros fossem direcionados para o atendimento a especificidades comerciais, logísticas, industriais, históricas e ambientais (IPPUC - Planmob anexo ii, 2008, p.6).

É a partir dessas proposições que se criou um sistema de transporte de ônibus de massa capaz de articular com as funções básicas, descritas anteriormente, do planejamento urbano de

$\begin{array}{llllll}\text { Caminhos de Geografia } & \text { Uberlândia - MG } & \text { v. 19, n. } 67 & \text { Set/2018 } & \text { p. 361-373 Página } 366\end{array}$


Curitiba. O IPPUC realizou um estudo na cidade sobre a implantação do sistema de transporte metroviário, mas o custo operacional foi considerado inviável e, por isso, optou-se em planejar um sistema integrado de transporte coletivo de superfície, que tem custos menores do que os sistemas sobre trilhos (IPPUC, 2015; LERNER, 2009).

Então, em 1974 teve início a operação de duas linhas de ônibus expressos circulando em canaletas exclusivas, a interligar os eixos estruturais norte e sul a partir do centro da cidade. A operacionalização era composta por dois terminais de integração e linhas alimentadoras (IPPUC, 2008). À medida que se expandia o espaço urbano de Curitiba, consolidava-se o sistema viário e a rede integrada de transporte de ônibus.

Essa proposta de transporte público marca o surgimento da noção de um sistema de trânsito rápido de ônibus, atualmente denominado pelas siglas em inglês BRT - Bus Rapid Transit. A origem do termo "Rapid Transit" (trânsito rápido) está ligada às primeiras faixas exclusivas destinadas aos ônibus expressos nos Estados Unidos (express buses) e na França (Bus à Haut Niveau de Service) (LERNER, 2009). Porém, o aprimoramento operacional e, a posteriori, tecnológico, desenvolveu o modelo como é conhecido hoje.

Com base no documento "Manual de BRT", produzido por algumas instituições internacionais e publicado no Brasil através do Ministério das Cidades (2008, p.1), o conceito de BRT se refere a implantação de um "sistema de transporte por ônibus que proporciona mobilidade urbana rápida, confortável e com custo eficiente através da provisão de infraestrutura segregada com prioridade de passagem, operação rápida e frequente e excelência em marketing e serviço ao usuário".

Lerner $(2009,2013)$ e IPPUC $(2008)$ ajudam a esclarecer que o fundamento conceitual do BRT está baseado na efetivação de um planejamento de transporte, ou seja, um plano de mobilidade urbana, que possa ser revisado conforme as necessidades da cidade e que a utilização de vias segregadas para ônibus de alta capacidade esteja operando em conjunto com uma rede integrada de transporte alinhada à organização do espaço urbano.

Este conceito materializou-se em 1979 através da criação da Rede Integrada de Transporte (RIT) de Curitiba, incluindo as áreas fora do sistema estrutural (LERNER, 2009; IPPUC, 2015). A extensão de novos eixos para implantação de canaletas exclusivas para ônibus entre 1980 e 2014, sem a introdução de novos modais de transporte, como o metrô, demonstram como algun s dos planejadores de Curitiba, como Jaime Lerner, defendem a cultura do BRT, ou seja, a infraestrutura desse modal tornou-se uma identidade daquele território.

A "inovação" no setor de mobilidade urbana, o planejamento e a ordenação do espaço urbano foram os componentes essenciais para que o marketing de cidade modelo, desenvolvido pelos agentes públicos em Curitiba, colocasse em evidencia o "eficiente" modo de gestão e o produto de suas políticas públicas desenvolvimentistas (SÁNCHEZ, 2010). Ou seja, trata-se de um processo de operacionalização institucional que aderiu ao chamado planejamento estratégico que, conforme Harvey (1996), Sánchez (2010) e Souza (2013) pode ser entendido como um método adotado por algumas cidades para "empresariar", e não gerenciar a organização do espaço urbano. E a partir do produto de uma renovação urbana, sustenta-se a noção de um modelo para efetivar o marketing urbano. Este, por consequência, pode exagerar sobre a qualidade ou escamotear a obsolescência do projeto proposto pela city marketing.

O planejamento estratégico geralmente é adotado por governos de cidades que se submetem às mesmas condições administrativas das empresas, com o objetivo de formular políticas de desenvolvimento urbano sobre o ponto de vista do capital (HARVEY, 1996; VAINER 2009). Tratase de novas estratégias para adaptar as diretrizes do Plano Diretor, através das parcerias entre agentes públicos e privados, constituindo elementos fundamentais para renovação urbana (SÁNCHEZ, 2010). Nesse sentido, o espaço urbano tem sido adaptado, ou "renovado", às flexibilidades sobrepostas à reprodução social (CARLOS, 2011), mediante a aplicação de técnicas modernas que tornam a organização desse espaço um modelo para ser disseminado através do marketing urbano.

Para Vainer (2009) o planejamento estratégico tem atuado como legitimador da cooperação público-privada. E as articulações que envolvem essa "parceria" em formato de política pública, não alcançam a totalidade do espaço, mas, seleciona-o mediante os interesses dos grupos econômicos. Segundo Sánchez (2010), o planejamento estratégico e o marketing urbano têm sido apresentados como instrumentos adequados e promissores em cidades latinas, como ocorrido em Curitiba-PR e Rio de Janeiro-RJ.

$\begin{array}{llllll}\text { Caminhos de Geografia } & \text { Uberlândia - MG } & \text { v. 19, n. } 67 & \text { Set/2018 } & \text { p. 361-373 } & \text { Página } 367\end{array}$


Curitiba expandiu seus arquétipos de city marketing para várias cidades no Brasil e no exterior. O modelo advindo do planejamento, zoneamento e, principalmente, do transporte urbano foi difundido em várias cidades do país e, através de revisões dos planos diretores, buscam adaptálo aos seus espaços, mesmo com diferenças socioespaciais.

A problemática do transporte público vivenciada nas metrópoles, como engarrafamentos, baixo índice de acessibilidade pela má qualidade do fluxo urbano, acarretando problemas sociais, também estão presentes em cidades de porte médio. Os projetos de BRT geralmente tem a finalidade de reduzir o fluxo de veículos motorizados particulares nas principais vias das cidades, com objetivo de promover a estruturação viária, mobilidade urbana, acessibilidade ao espaço urbano, além de intervenções arquitetônicas pontuais que valorizam o seu entorno.

Por isso, as propostas de implantação do BRT surgem como uma alternativa aparentemente viável para auxiliar o sistema de transporte urbano, melhorando a qualidade de vida dos usuários. Embora essa garantia da reprodução social possibilite a "renovação" do espaço urbano, delimitado pelos interesses do capital.

As interfaces de um projeto de Mobilidade Urbana que se tornou modelo no país e no mundo devem ser estudadas de forma crítica, a fim de colaborar para a eficiência das futuras implantações. Observar os projetos que já estão em funcionamento, através de recortes regionais, propicia maior compreensão das questões até aqui abordadas. Nesse intuito, foi realizado um levantamento sobre os projetos de BRT já implantados no Brasil, seguindo a metodologia e os conceitos específicos ao modo. A figura 1 apresenta esse levantamento, elencando as cidades contempladas, a população à época da implantação e o tipo de sis tema em funcionamento. Nela, é esclarecido que o Brasil possui o sistema implantado em dez cidades distribuídas em sete estados e o Distrito Federal.

É apontado na figura 1 o panorama da difusão do sistema BRT desde o primórdio de sua implantação em Curitiba-PR em 1974, até o último sistema inaugurado, o BRT Transolímpica, em agosto de 2016 na cidade do Rio de Janeiro. O segundo BRT inaugurado no Brasil foi o de Goiânia-GO em 1976, chamado Expresso Anhanguera. O Corredor Metropolitano ABD, que liga a zona leste à zona sul de São Paulo, atravessa quatro municípios, entre eles, Mauá, Santo André, São Bernardo do Campo e Diadema. Foi o primeiro sistema do tipo a operar na Região Metropolitana de São Paulo. É a região mais populosa a implantar o BRT. Já o município de Uberaba-MG é o único a implantar o BRT com população abaixo de trezentos e vinte mil habitantes.

Constatou-se que os investimentos do PAC mobilidade Urbana só foram destinados a execução de obras de BRT a partir de 2008, e a primeira obra inaugurada foi a extensão do Corredor Metropolitano ABD Morumbi (RMSP), em 2010. Mas, é expressiva a quantidade de projetos de BRT em análise para financiamento pelo PAC (figura 2), principalmente, a partir de 2011 (MINISTÉRIO DO PLANEJAMENTO, 2016).

Alguns projetos de BRT foram alterados, como em Recife-PE. O projeto foi financiado como um corredor de BRT, mas a operacionalização do sistema permite que outros veículos circulem em alguns trechos dos corredores, aumentando o tempo de deslocamento dos ônibus. O mesmo acontece nas obras de expansão do sistema BRT em Uberlândia-MG e Uberaba-MG. Neste último, as alterações foram feitas por conta da pressão dos comerciantes que possuem estabelecimentos nos trechos com corredores, que sinalizaram prejuízos desde o início das obras. As alterações no projeto nessas cidades devem influenciar diretamente na funcionalidade do sistema BRT, e poderá levantar discussões sobre os interesses que envolvem: os comerciantes (com a queda nas vendas), o Estado (e o lobby com agentes imobiliários na produção e valorização desigual do espaço urbano) e os usuários do transporte público (principais atingidos pelas mudanças do sistema de transporte - afirmação conferida através de diálogos com usuários que residem em áreas periféricas das cidades de Uberaba e Uberlândia).

Para entender o processo de difusão do BRT, na figura 2 é apresentado o levantamento sobre as obras concluídas, em execução, licitação, estudo ou ação preparatória. Verificou-se que os projetos destacados e que estão em execução ou ação preparatória respaldam -se nas diretrizes da Política Nacional de Mobilidade Urbana. 
Figura 1: Cidades no Brasil que implantaram o Sistema BRT

\begin{tabular}{|c|c|c|c|}
\hline \multicolumn{4}{|c|}{ SISTEMAS BRT IMPLATADOS NO BRASIL ENTRE 1974 E 2016} \\
\hline CIDADE & ESPECIFICAÇÕES & $\begin{array}{c}\text { ANO DE } \\
\text { IMPLANTAÇÃO }\end{array}$ & $\begin{array}{l}\text { POPULAÇÃO Ȧ } \\
\text { ÉPOCA DA } \\
\text { IMPLANTAÇÃO }\end{array}$ \\
\hline \multirow[t]{4}{*}{ Curitiba - PR } & $\begin{array}{l}\text { Surgimento da noção de BRT, com a } \\
\text { implantação do Eixo Estrutural Norte e Sul, } \\
\text { com terminais, estações e vias exclusivas (e } \\
\text { segregadas) para ônibus. }\end{array}$ & 1974 & \multirow[t]{3}{*}{$\begin{array}{l}624.362 \text { hab. } \\
\text { (Década de 1970) }\end{array}$} \\
\hline & 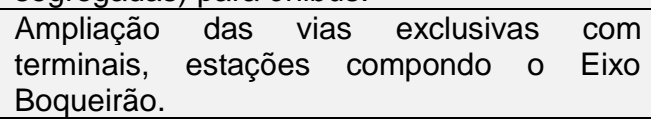 & 1977 & \\
\hline & $\begin{array}{l}\text { Criação da Rede Integrada de Transporte } \\
\text { (RIT), que efetiva o conceito de BRT. }\end{array}$ & 1979 & \\
\hline & $\begin{array}{l}\text { Implantação dos eixos Leste e Oeste com } \\
\text { vias exclusivas para ônibus. }\end{array}$ & 1980 & 1.052.147 hab. \\
\hline $\begin{array}{l}\text { Região } \\
\text { Metropolitana de } \\
\text { Curitiba - PR } \\
\end{array}$ & $\begin{array}{l}\text { Extensão da via exclusiva para ônibus entre } \\
\text { o Eixo Boqueirão e terminal em São José } \\
\text { dos Pinhais - PR (Região Metropolitana). }\end{array}$ & 2014 & 3.414.115 hab. \\
\hline Goiânia - GO & Implantação do BRT Eixo Anhanguera. & 1976 & 389.724 hab. \\
\hline Uberlândia - MG & $\begin{array}{l}\text { Implantação do BRT Sistema Integrado de } \\
\text { Transporte (SIT). }\end{array}$ & 2006 & 501.214 hab. \\
\hline $\begin{array}{l}\text { Região } \\
\text { Metropolitana de } \\
\text { São Paulo - SP }\end{array}$ & $\begin{array}{l}\text { Implantação do Corredor Metropolitano ABD. } \\
\text { É considerado um sistema BRT**. }\end{array}$ & 1988 & $\begin{array}{c}\text { RMSP } \\
12.588 .725 \text { hab. }\end{array}$ \\
\hline São Paulo - SP & Implantação do BRT Expresso Tiradentes. & 2006 & $\begin{array}{c}\text { Município } \\
10.434 .252 \text { hab. }\end{array}$ \\
\hline $\begin{array}{l}\text { Região } \\
\text { Metropolitana de } \\
\text { São Paulo - SP } \\
\end{array}$ & $\begin{array}{l}\text { Implantação da Extensão Morumbi do } \\
\text { Corredor Metropolitano ABD. BRT }{ }^{\star \star *} \text { básico. }\end{array}$ & 2010 & $\begin{array}{c}\text { RMSP } \\
\text { 19.683.975 hab. }\end{array}$ \\
\hline \multirow{3}{*}{$\begin{array}{l}\text { Rio de Janeiro - } \\
\text { RJ }\end{array}$} & Implantação do BRT Transoeste & 2012 & \multirow[t]{2}{*}{ 6.320.446 hab. } \\
\hline & Implantação do BRT Transcarioca & 2014 & \\
\hline & Implantação do BRT Transolímpica & 2016 & 6.498.837 hab. \\
\hline $\begin{array}{l}\text { Região Integrada } \\
\text { de } \\
\text { Desenvolvimento } \\
\text { (RIDE) do Distrito } \\
\text { Federal e entorno }\end{array}$ & BRT Expresso DF Sul & 2014 & 4.118.154 hab. \\
\hline \multirow[t]{2}{*}{$\begin{array}{l}\text { Belo Horizonte - } \\
\text { MG }\end{array}$} & $\begin{array}{l}\text { Implantação do BRT MOVE Cristiano } \\
\text { Machado }\end{array}$ & \multirow[t]{2}{*}{2014} & \multirow[t]{2}{*}{ 2.375.151hab. } \\
\hline & Implantação do BRT MOVE Antônio Carlos & & \\
\hline \multirow{2}{*}{$\begin{array}{l}\text { Região } \\
\text { Metropolitana de } \\
\text { Recife - PE* }\end{array}$} & Implantação do BRT Via Livre Norte/Sul & \multirow[t]{2}{*}{2014} & \multirow[t]{2}{*}{ 3.887.261 hab. } \\
\hline & Implantação do BRT Via Livre Leste/Oeste & & \\
\hline Uberaba - MG & Implantação do BRT Vetor Leste/Oeste & 2015 & 318.813 hab. \\
\hline $\begin{array}{l}\text { Região } \\
\text { Metropolitana de } \\
\text { Fortaleza-CE } \\
\end{array}$ & $\begin{array}{l}\text { Inauguração de trecho do BRT - Av. Antônio } \\
\text { Bezerra. }\end{array}$ & 2015 & 3.818.380 hab. \\
\hline
\end{tabular}

(*) Apesar do projeto do novo sistema de transporte de Recife ter sido financiado como BRT, apresenta falhas na infraestrutura e na operacionalização como o longo tempo de viagem causado pela falta de segregação física entre a faixa de ônibus e a vias de veículos particulares, que desqualificam o conceito do sistema. O Governo Federal (MINISTÉRIO DO PLANEJAMENTO, 2015) assume que em Recife o sistema funciona como BRT, enquanto que o Instituo de Políticas de Transporte e Desenvolvimento (ITPD, 2016) e os conceitos defendidos por Jaime Lerner $(2009$; 2013) contestam essa questão.

$\left({ }^{* *}\right)$ O Corredor Metropolitano ABD atende os municípios de Diadema, São Bernardo do Campo, Santo André e Mauá, todos compondo a Região Metropolitana de São Paulo. Apresenta características semelhantes a um sistema BRT e, por isso é assim classificado pelo Instituo de Políticas de Transporte e Desenvolvimento (ITDP, 2016), uma das instituições envolvidas na elaboração do "Manual de BRT" (MINISTÉRIO DAS CIDADES, 2008). $\left.{ }^{* * *}\right)$ O Corredor Extensão Morumbi é uma ampliação do Corredor Metropolitano ABD e, por isso é considerado pelo ITPD (2016) um BRT com funções básicas.

Fonte: A partir de: IPPUC (2008, 2015), LERNER (2013), MINISTÉRIO DO PLANEJAMENTO (2015), MINISTÉRIO DAS CIDADES (2008), ITDP (2016), NTU (2015), EMTU - SP (2016), BRT/RIO (2016), Empresa de Transporte Urbano de Fortaleza (ETUFOR), BRT VIA LIVRE - Recife (2016), IBGE (2014), IBGE (Censo Demográfico de 1970, 1980, 1991, 2000 e 2010). Organizado pelo autor. 
Figura 2: Cidades no Brasil que estão em processo de implantação/expansão do BRT

\begin{tabular}{|c|c|c|c|c|c|c|}
\hline \multicolumn{7}{|c|}{ DIAGNÓSTICO DA DIFUSÃO DO SISTEMA BRT NO BRASIL (até dezembro de 2016) } \\
\hline $\begin{array}{l}\text { CLASSES DE } \\
\text { TAMANHO } \\
\text { DA } \\
\text { POPULAÇÃO }\end{array}$ & UF & $\begin{array}{l}\text { EM } \\
\text { FUNCIONAMENTO }\end{array}$ & $\begin{array}{l}\text { EM } \\
\text { OBRAS }\end{array}$ & $\begin{array}{l}\text { FASE DE } \\
\text { EXPANSÃO }\end{array}$ & $\begin{array}{l}\text { EM } \\
\text { ESTUDO }\end{array}$ & $\begin{array}{l}\text { AÇÃ́O } \\
\text { PREPARATÓRI } \\
\text { A/ } \\
\text { LICITAÇÃO/ } \\
\text { FINALIZAÇÃO } \\
\text { DE PROJETO } \\
\end{array}$ \\
\hline \multirow{6}{*}{$\begin{array}{l}\text { De } 100.000 \text { a } \\
500.000\end{array}$} & MG & Uberaba & - & Uberaba & - & - \\
\hline & SP & - & - & - & - & $\begin{array}{c}\text { Jundiaí } \\
\text { Praia grande }\end{array}$ \\
\hline & RJ & - & - & - & - & Niterói \\
\hline & PE & - & - & - & - & Caruaru \\
\hline & GO & - & - & - & - & Luziânia \\
\hline & TO & - & - & - & - & Palmas \\
\hline \multirow{6}{*}{$\begin{array}{l}\text { De } 500.001 \mathrm{a} \\
1.000 .000\end{array}$} & MG & Uberlândia & - & Uberlândia & - & - \\
\hline & GO & - & - & - & - & $\begin{array}{l}\text { Aparecida de } \\
\text { Goiânia }\end{array}$ \\
\hline & SP & - & $\begin{array}{c}\text { São José } \\
\text { dos } \\
\text { Campos }\end{array}$ & - & - & Sorocaba \\
\hline & PB & - & - & - & - & João Pessoa \\
\hline & PR & - & - & - & - & Londrina \\
\hline & BA & - & - & - & - & $\begin{array}{l}\text { Feira de } \\
\text { Santana }\end{array}$ \\
\hline \multirow{15}{*}{$\begin{array}{l}\text { Acima de } \\
1.000 .001\end{array}$} & PR & Curitiba & - & Curitiba & - & R.M. Curitiba \\
\hline & GO & Goiânia & - & - & - & Goiânia \\
\hline & SP & R.M. São Paulo & - & - & - & Campinas \\
\hline & RJ & Rio de Janeiro & - & Rio de Janeiro & - & - \\
\hline & DF & RIDE & Brasília & RIDE & RIDE & Brasília \\
\hline & MG & Belo Horizonte & - & - & - & - \\
\hline & PE & R.M. Recife & - & - & - & R. M. Recife \\
\hline & CE & R.M. Fortaleza & $\begin{array}{c}\text { R.M. } \\
\text { Fortaleza }\end{array}$ & R.M. Fortaleza & - & R.M. Fortaleza \\
\hline & PA & - & Belém & - & - & - \\
\hline & $\mathbf{A L}$ & - & - & - & - & Maceió \\
\hline & AM & - & - & - & - & Manaus \\
\hline & RN & - & - & - & - & Natal \\
\hline & BA & - & - & - & - & Salvador \\
\hline & MA & - & - & - & - & São Luís \\
\hline & RS & - & $\begin{array}{l}\text { Porto } \\
\text { Alegre }\end{array}$ & - & - & - \\
\hline
\end{tabular}

Fonte: A partir de: IPPUC (2008, 2015), MINISTÉRIO DO PLANEJAMENTO (2015), MINISTÉRIO DAS CIDADES (2008), ITDP (2016), NTU (2015), EMTU - SP (2016), Governo do Distrito Federal, Prefeitura Municipal de Curitiba, BRT/RIO (2016), Empresa de Transporte Urbano de Fortaleza (ETUFOR), BRT VIA LIVRE

- Recife (2016), IBGE 2015 (Estimativas da população nos municípios em 2015). Organizado pelo autor.

Os empreendimentos do BRT estão espalhados por dezesseis estados e no Distrito Federal e, cabe aqui enfatizar, que essa difusão só foi possível através de políticas federais que permitiram o financiamento desse sistema de transporte, como o PAC 2: mobilidade urbana. A maioria das obras concluídas está localizada em capitais com população acima de um milhão de habitantes. Mesmo com problemas funcionais e operacionais (como por exemplo, a superlotação dos ônibus, mudanças nos itinerários, falta de segurança nos terminais e nas estações), as cidades de Belo Horizonte e do Rio de Janeiro estão em fase de expansão do sistema BRT, assim como em outros três municípios e o Distrito Federal, como destacado na figura 2. Em cinco capitais predominantemente da região norte e nordeste já possuem projetos que estão em ação preparatória. As pesquisas mostraram que seis municípios com população entre cem mil a quinhentos mil habitantes já apresentam projetos para implantação do sistema BRT em fase avançada, assim como outros cinco municípios com população entre quinhentos mil a um milhão de habitantes.

A figura apresentada mostra que houve uma rápida difusão do modelo de transporte coletivo BRT em diversas cidades brasileiras, processo intensificado a partir de 2011. As políticas de transporte $\begin{array}{llllll}\text { Caminhos de Geografia } & \text { Uberlândia - MG } & \text { v. 19, n. } 67 & \text { Set/2018 } & \text { p. 361-373 } & \text { Página } 370\end{array}$ 
coletivo das cidades de grande, e atualmente, de médio porte têm absorvido recursos do PAC mobilidade para realização de projetos de implantação ou expansão de BRT. Enfatiza-se que a criação da Lei Federal de Mobilidade Urbana, Estatuto da Cidade e Ministério das Cidades, constituem instrumentos essenciais que viabilizaram projetos como estes. Ressalta-se a importância disso, já que se constituiu, mesmo com alguns problemas nos sistemas, num avanço na área de transporte urbano nas cidades no qual foi implantado.

\section{CONSIDERAÇÕES FINAIS}

$\mathrm{Na}$ virada do século XXI houve avanços das políticas de transporte urbano que, ao longo dos anos, levaram a difusão do sistema BRT em algumas cidades brasileiras. Essas políticas acontecem em grandes centros urbanos e agora nas cidades de porte médio, inserindo lógicas específicas aos usos do sistema de transporte urbano e a produção do espaço e que devem ser analisadas de acordo com suas especificidades.

O planejamento do transporte urbano atualmente, no Brasil, perpassa pela consideração da criação do BRT em Curitiba, que apesar de ser um projeto de caráter mercadológico onde a parceria públicoprivada promoveu novas estratégias para se estabelecer as políticas de transportes coletivos, aquele planejamento conseguiu atender parcialmente as necessidades sociais (SANCHEZ, 2010).

As intenções políticas que constroem o "projeto urbano" atuam no espaço de forma estratégica. E que o BRT é concebido por meio dessas políticas ditas "eficientes" e que essa lógica já se encontra numa expressiva difusão. Na verdade, o BRT atende parte das necessidades sociais, enquanto que ele mesmo delimita as novas zonas periféricas das cidades.

Os problemas que envolveram a implantação do BRT em Uberaba-MG e Recife-PE, por exemplo, evidenciam através dos conflitos que esse sistema é um elemento para a produção do espaço e das práticas do planejamento urbano. Ainda que a instalação do sistema seja recente em Uberaba, assim como em Belo Horizonte-MG, os problemas do transporte são recorrentes: os comerciantes situados ao longo dos corredores persistem em reclamar do BRT, o sistema operacional não contribui para a agilidade da circulação do ônibus expresso, o sistema viário está em evolução, com obras em pontos estratégicos das cidades para desafogar o trânsito ao longo dos corredores, embora os congestionamentos nas áreas centrais e no entorno sejam frequentes.

Enfatiza-se que o BRT é um instrumento que possibilita a produção do espaço e às práticas do planejamento urbano, mediante ações estratégicas do poder público. Os conflitos sócio-espaciais estão presentes na realização de empreendimentos de transporte público urbano como o BRT, que modelam o espaço e emergem conforme os interesses de variados agentes sociais, como verificado na atualização de projetos de expansão do BRT mencionados anteriormente, que objetivaram atender os interesses dos comerciantes, agentes imobiliários e do Estado.

\section{AGRADECIMENTOS}

O desenvolvimento desta pesquisa só foi possível através do financiamento da Fundação Carlos Chagas Filho de Amparo à Pesquisa do Estado do Rio de Janeiro (FAPERJ). Com os recursos disponibilizados, realizou-se os trabalhos em campo e pesquisas externas.

\section{REFERÊNCIAS}

Associação Nacional dos Fabricantes de Veículos Automotores (ANFAVEA). Estatísticas: séries temporais. Disponível em: <<http://www.anfavea.com.br/estat\%C3\%ADsticas.html >>. Acesso em: 20/03/2016.

Associação Nacional das Empresas de Transportes Urbanos. Anuário NTU 2014/2015. Brasília, 2015.

BRASIL. Lei 12.587/12 que trata da Política Nacional de Mobilidade Urbana.

BRASIL. Lei 10257/01 que dispõe do Estatuto da Cidade.

BRASIL, MINISTÉRIO DAS CIDADES. Manual de BRT. 2008.

BRASIL, MINISTÉRIO DAS CIDADES. Resultados, projeções e ações. 2008.

\begin{tabular}{llllll}
\hline Caminhos de Geografia & Uberlândia - MG & v. 19, n. 67 & Set/2018 & p. 361-373 & Página 371
\end{tabular}


BRASIL, MINISTÉRIO DAS CIDADES. Mecanismos de financiamento: curso de capacitação para o Plano de Mobilidade Urbana. 2014.

BRASIL, MINISTÉRIO DAS CIDADES. Resumo de empreendimentos de mobilidade. 2016.

BRASIL, MINISTÉRIO DO PLANEJAMENTO. 11ํㅡㄹ Balanço do Programa de Aceleração do Crescimento. 2015.

BRASIL. SENADO FEDERAL - Estatuto da Cidade. Disponível em: <<http://www.senado.gov.br/senado/Programas/EstatutodaCidade/oquee.htm >>. Acesso em: 01/04/2016.

CARLOS, Ana Fani Alessandri. Da "organização" à "produção" do espaço no movimento do pensamento geográfico. In: CARLOS, Ana Fani Alessandri. SOUZA, Marcelo Lopes. SPÓSITO, Maria Encarnação Beltrão (Orgs.). A produção do espaço urbano: agentes e processos, escalas e desafios São Paulo: Contexto, 2011.

CONSTITUIÇÃO DA REPÚBLICA FEDERATIVA DO BRASIL, 1988.

DUARTE, Fábio. Planejamento urbano. Curitiba: Ibpex, 2007.

Empresa Metropolitana de Transportes Urbanos de São Paulo (EMTU-SP), 2016.

FENABRAVE, Anuário 2012.

FREITAS, Maria Cristina Penido de. Os efeitos da crise global no Brasil: aversão ao risco e preferência pela liquidez no mercado de crédito. Estudos avançados, São Paulo, v. 23, n. 66, p.125145, 2009.

Grande Recife. BRT Via Livre, 2016.

HARVEY, David. Do gerenciamento ao empresariamento: a transformação da administração urbana no capitalismo tardio. São Paulo, Espaço e Debates, no 39, 1996, p. 48-64.

IBGE. Censos Demográficos de 1940, 1950, 1960, 1970, 1980, 1991, 2000 e 2010.

IBGE. Cidades de porte médio. Brasil, 2014.

IPPUC. Instituto de Pesquisa e Planejamento Urbano de Curitiba, 2016.

IPPUC. Instituto de Pesquisa e Planejamento Urbano de Curitiba. Plano Diretor de Curitiba, 2008.

IPPUC. Instituto de Pesquisa e Planejamento Urbano de Curitiba. Plano de Mobilidade Urbana, 2008.

IPPUC. História do planejamento urbano em Curitiba, 2015

ITDP. Corredores de BRT Ranqueados pelo ITDP Brasil. Disponível em:

<<http://itdpbrasil.org.br/rankingbrt/>>. Acesso em: 14/07/2016.

LERNER, Jaime. Relatório Final BRT Uberaba. Curitiba, 2010.

LERNER, Jaime. Avaliação comparativa das modalidades de transporte público urbano. Curitiba: NTU, 2009.

LERNER, Jaime. O desafio da mobilidade, cidades e qualidade de vida. In: Mobilidade Sustentável para um Brasil Competitivo. Brasília: NTU, 2013.

MARICATO, Ermínia. O Ministério das Cidades e a política nacional de desenvolvimento urbano: Cidades brasileiras: a matriz patrimonialista. Políticas Sociais (IPEA), v. 12, p. 211-220, 2006.

MARICATO, Ermínia. As ideias fora do lugar e o lugar fora das ideias. In: A cidade do pensamento único: desmanchando consensos. 5.ed. Petrópolis: Vozes, 2009.

MARICATO, Ermínia. O Estatuto da Cidade Periférica. In: CARVALHO, Celso Santos. ROSSBACH, Anaclaudia (ogrs). O Estatuto da Cidade comentado. São Paulo: Ministério das Cidades : Aliança das Cidades, 2010.

MARICATO, Ermínia. Brasil, cidades: alternativas para a crise urbana. Petrópolis: Vozes, 2011.

PREFEITURA DA CIDADE DO RIO DE JANEIRO. BRT/RIO. 2016.

PREFEITURA MUNCIPAL DE CURITIBA. Urbanização de Curitiba - 1943. PMC, 2016.

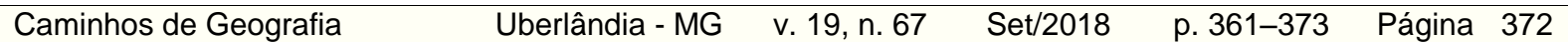


Prioridade ao transporte público por ônibus: panorama dos projetos e investimentos. Brasília: NTU, 2015.

ROCHEFORT, Michel. O desafio urbano nos países do Sul. Campinas, Edições territorial, 2008. p. 43-118.

SÁNCHEZ, Fernanda. A reinvenção das cidades para um mercado mundial. 2. ed. Chapecó: Argos, 2010.

SOUZA, Marcelo Lopes de. Mudar a Cidade: uma introdução crítica ao planejamento e à gestão urbanos. 9. ed. Rio de Janeiro: Bertrand Brasil, 2013.

URBS. Urbanização de Curitiba, 2016.

VAINER, C. Pátria, empresa e mercadoria: notas sobre a estratégia discursiva do Planejamento Estratégico Urbano. In: ARANTES, Otília. VAINER, Carlos. MARICATO, Ermínia. A cidade do pensamento único: desmanchando consensos. 5.ed. Petrópolis: Vozes, 2009.

VASCONCELLOS, Eduardo Alcântara de. Políticas de transporte no Brasil: a construção da mobilidade excludente. Barueri: Manoele, 2013.

VILLAÇA, Flávio. Uma contribuição para a história do planejamento urbano no Brasil. In: DEÁK, Csaba. SCHIFFER, Sueli Ramos (orgs.). 0 processo de Urbanização no Brasil. São Paulo: Editora Universidade de São Paulo, 1999, p.170-243.

VILLAÇA, Flávio. A problemática do transporte urbano no Brasil. In: SILVEIRA, Márcio Rogério Silveira (org.). Circulação, transportes e logísticas diferentes perspectivas'. São Paulo: Outras Expressões, 2011.

Recebido em: 03/01/2017

Aceito para publicação em: 21/05/2018 